\title{
Análise da mutação G20210A no gene da protrombina (fator II) em pacientes com suspeita de trombofilia no sul do Brasil
}

\author{
Analysis of prothrombin G20210A mutation (factor II) in patients with suspected trombophilia in Southern Brazil
}

Marcos Edgar Herkenhoff'; Rodrigo Gaulke²; Jaqueline Godinho de Souza $;$ Nadir Schmidt Thomé ${ }^{4}$; Ana Kelly Pitlovanciv ${ }^{5}$ Vanessa Rosália Remualdo ${ }^{6}$

unitermos
Protrombina
Mutação
G20210A
RT-PCR
SNP

\section{resumo}

Introdução: A protrombina (fator II) é uma proteína sanguínea sintetizada no fígado com a presença de vitamina K. É a precursora da trombina, que induz a formação de fibrina. Foi descrita uma mutação no gene da protrombina G20210A, associada diretamente a altos níveis de protrombina no sangue e, consequentemente, à trombofilia. Essa variante alélica consiste em mutação pontual, também chamada de polimorfismo de nucleotídeo simples (SNP), ocasionando a troca de uma guanina por uma adenina no nucleotídeo 20210, localizado em um sítio de clivagem do precursor do ácido ribonucleico mensageiro (mRNA). Essa troca caracteriza o alelo $A$ e a ausência da mutação do alelo G. Objetivo: Quantificar o número de indivíduos homozigotos para alelo $\mathrm{G}$, homozigotos para alelo $\mathrm{A}$ e heterozigotos, cujas amostras foram enviadas para o laboratório Genolab Análises Genéticas, abrangendo os estados do Paraná e Santa Catarina, no período de $1^{\circ}$ de janeiro de 2009 a 10 de outubro de 2010. Métodos: Análise de mutação pontual por reação em cadeia da polimerase em tempo real (RT-PCR). Resultados: Obtivemos o número de 243 indivíduos e desse total $51,03 \%$ eram oriundos do estado do Paraná, enquanto $48,97 \%$, oriundos do estado de Santa Catarina. Do total analisado, $88,89 \%$ possuíam o genótipo para homozigoto G, e nenhum indivíduo foi encontrado com mutação para homozigoto $A$. Apenas $11,11 \%$ possuíam genótipo heterozigoto. $O$ estado de Santa Catarina apresentou frequência superior para genótipo heterozigoto em relação ao Paraná. Conclusão: Este estudo mostrou que é recomendável a identificação do genótipo para esse gene em pacientes com suspeita de trombofilia nos dois estados.

\section{abstract}

Introduction: Prothrombin (factor II) is a blood protein synthesized in the liver in the presence of vitamin $K$. It is a thrombin precursor, which induces fibrin formation. Prothrombin G20210A mutation and high prothrombin levels have been closely associated with thrombophilia. This allelic variant is a single mutation, also denominated single nucleotide polymorphism (SNP), in which guanine is replaced with adenine in the messenger ribonucleic acid (mRNA) cleavage of nucleotide 20210. The replacement is characterized by the presence of allele $A$ and the absence of mutation in allele $G$. Objective: To quantify the number of individuals homozygous for allele $G$, allele A and heterozygotes. The samples were collected in Paraná and Santa Catarina from January 15t, 2009 to October 10 th 2010 and were sent to Genolab Análises Genéticas. Methods: Analysis of single mutation by polymerase chain reaction in real time (RT-PCR). Results: From 243 individuals, $51.03 \%$ were from Paraná and $48.97 \%$ were from Santa Catarina. 88.89\% individuals were homozygous for $G$ genotype, none of them were homozygous for A. Only $11.11 \%$ were heterozygotes. Santa Catarina presented a higher frequency in heterozygous genotype in comparison with Paraná. Conclusion: This study showed that patients with suspected thrombophilia should undergo genotype identification in both states. key words

Prothrombin

Mutation

G20210A

RT-PCR

SNP

\footnotetext{
1. Mestrando em Ciência Animal (Genética); médico veterinário.

2. Graduando em Biomedicina; auxiliar de análises genéticas.

3. Graduanda em Biologia; auxiliar de análises genéticas.

4. Farmacêutica.

5. Mestra em Biotecnologia; responsável técnica do Cenolab Análises Cenéticas.

6. Doutora em Patologia; diretora cientíica do Cenolab Análises Cenéticas.
} 


\section{Introdução}

A protrombina, ou fator II de coagulação, é uma proteína sanguínea sintetizada no fígado com a presença de vitamina K. É precursora da trombina, que ao final da cascata de coagulação induz a formação de fibrina. Participando também dos mecanismos de controle de coagulação, ligando-se à trombomodulina e ativando o sistema da proteína $C$, tem papel fundamental no equilíbrio anticoagulante ${ }^{(10)}$.

As doenças tromboembólicas, por serem cosmopolitas, são uma das causas mais comuns de morbidade, incapacitação e mortalidade, com incidência na população geral de um caso para cada mil indivíduos por ano ${ }^{(7,10)}$.

O gene responsável pela protrombina contém aproximadamente $21.000 \mathrm{pb}$, composto de 14 éxons e 13 íntrons, localizado próximo ao centrômero no cromossomo $11^{(15)}$. Em 1996, foi descrita uma mutação na região 3', no gene da protrombina G20210A, que se associou diretamente a altos níveis de protrombina no sangue, sendo relatado como médio risco para a formação de tromboses venosas. Essa variante alélica consiste em uma mutação pontual, em que ocorre a troca de uma guanina base nitrogenada por uma adenina no nucleotídeo 20210 , localizada próxima a um sítio de clivagem do precursor do ácido ribonucleico mensageiro (mRNA), cuja cauda poli-A é adicionada. Essa mutação associa-se ao aumento de estabilidade do mRNA e de concentração plasmática da protrombina, o que parece ser o mecanismo que predispõe à ocorrência de trombose ${ }^{(10)}$.

O diagnóstico definitivo e laboratorial desse tipo de mutação sucede por meio de técnicas da biologia molecular. A investigação pelos níveis séricos de trombina é inviável de ser realizada devido à ocorrência da sobreposição entre os valores normais ${ }^{(2,10)}$. A técnica utilizada é a reação em cadeia da polimerase em tempo real (RT-PCR) e consiste na identificação dos alelos $G$ e $A$, podendo o indivíduo ser homozigoto para um dos alelos ou heterozigoto, possuindo um alelo de cada. $O$ alelo $G$ é não mutante, enquanto $o$ alelo $\mathrm{A}$ corresponde ao alelo mutante, em que ocorre a troca de uma guanina por uma adenina no nucleotídeo 20210 no gene da protrombina. Essa mutação, portanto, apresenta médio risco para trombose em indivíduos heterozigotos e homozigotos para alelo $A$; não apresenta risco em indivíduos homozigotos para o alelo $\mathrm{G}$.

Essa mutação encontra-se entre $1 \%$ e 3\% na população caucasiana, com risco de 2,8 vezes para trombose. Não foi encontrada essa mutação em pacientes negros ou asiáticos até o momento, indicando que nesses grupos a mutação não tem frequência ou possui frequência extremamente

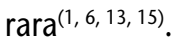

No Brasil, dispomos de poucos dados na literatura especializada devido a esse fator de risco ser relativamente recente e, até o momento, não foram verificadas bibliografias a respeito da incidência da mutação da protrombina nos indivíduos da região sul do Brasil.

O objetivo deste trabalho foi quantificar o número de indivíduos homozigotos para alelo $\mathrm{G}$, homozigotos para alelo $\mathrm{A}$ e heterozigotos. Os exames solicitados foram enviados para o laboratório Genolab Análises Genéticas, no período de $1^{\circ}$ de janeiro de 2009 a 10 de outubro 2010, abrangendo os estados do Paraná e de Santa Catarina. Este estudo poderá fornecer dados para a literatura, favorecendo a consulta da incidência dos genótipos da protrombina em indivíduos dos estados da região sul do Brasil.

\section{Métodos}

\section{Obtenção e coleta do material}

Foram utilizadas para o presente trabalho amostras de sangue periférico enviadas pelos laboratórios conveniados ao Genolab, localizado na cidade de Blumenau-SC, pertencentes aos estados do Paraná e de Santa Catarina. Foi recomendado que a coleta realizada seguisse o manual de coleta Genolab 2010:

- amostras refrigeradas $\left(4^{\circ} \mathrm{C}\right.$ em até três dias);

- nenhuma orientação no preparo do paciente;

- volume de $5 \mathrm{ml}$ de sangue periférico e condicionados em tubos contendo anticoagulante ácido etilenodiaminotetracético (EDTA).

\section{Extração de DNA e amplificação}

Para obtenção e isolamento do ácido desoxirribonucleico (DNA), utilizou-se a técnica de fenol/clorofórmio ${ }^{(12)}$. Para amplificação do material genético de interesse, foi aplicada a técnica de RT-PCR, com sonda Taqman ${ }^{\circledR}$, e as concentrações dos reagentes aplicados foram de acordo com as recomendações do fabricante (Applied, Foster City,CA). A RT-PCR é uma metodologia que permite a quantificação dos produtos de amplificação gênica com acompanhamento da reação em cadeia da polimerase (PCR) em todas as fases e ciclos. Por esse motivo, ela dispensa o uso da eletroforese convencional, tornando o serviço muito mais ágil(4). 
A vantagem de se utilizar a RT-PCR é que essa técnica possui sensibilidade muito maior quando em comparação com a PCR convencional, permitindo a detecção de baixas concentrações de material genético na amostra ${ }^{(4)}$.

\section{Análise dos laudos e análise estatística}

Os resultados dos laudos de exames foram consultados para o gene da protrombina, oriundos do banco de dados do Genolab, entre o período de $1^{\circ}$ de janeiro de 2009 e 10 de outubro de 2010. Quantificaram-se, assim, amostras de 243 indivíduos.

Depois de obter e analisar os laudos, foi feita a análise estatística e calculou-se a frequência genotípica alélica da amostra.

\section{Resultados}

No total da amostra, 20,16\% dos indivíduos eram do sexo masculino, enquanto $79,84 \%$, do sexo feminino. Em relação aos estados, essa proporção variou. No estado do Paraná, $16,13 \%$ eram do sexo masculino e $83,87 \%$, do sexo feminino; no estado de Santa Catarina, 24,37\% eram do sexo masculino e $75,63 \%$, do sexo feminino (Figura). O número maior de solicitações de exame para o sexo feminino deve-se ao fato de essa trombofilia associar-se a problemas na gestação, inclusive em abortos relacionados com o primeiro trimestre ${ }^{(9)}$.

Do total analisado, $88,89 \%$ dos indivíduos possuíam genótipo para homozigoto $G$. Não foi detectado nenhum indivíduo para genótipo homozigoto $\mathrm{A}$, enquanto $11,11 \%$ possuíam genótipo heterozigoto. Em relação aos valores totais dos indivíduos do estado do Paraná,
$92,74 \%$ tinham genótipo homozigoto G e 7,26\%, genótipo heterozigoto. No estado de Santa Catarina, os valores foram um pouco diferentes: $84,87 \%$ apresentaram genótipo homozigoto $\mathrm{G}$ e 15,13\%, genótipo heterozigoto (Tabela 1).

Em relação aos valores de cada sexo, $81,64 \%$ do total de indivíduos do sexo masculino possuíam genótipo homozigoto G e 18,36\%, genótipo heterozigoto. No estado do Paraná, a proporção mostrou que $80 \%$ dos indivíduos da amostra masculina apresentavam genótipo homozigoto $G$, enquanto o restante, $20,0 \%$, apresentava genótipo heterozigoto. No estado de Santa Catarina, a proporção não foi muito diferente, pois $82,76 \%$ do total de indivíduos masculinos apresentavam genótipo $\mathrm{G}$, enquanto $17,24 \%$ eram genótipo heterozigoto (Tabela 2).

\section{Frequência nos sexos no Paraná, em}

Tabela 1 Santa Catarina e no total

\begin{tabular}{|c|c|}
\hline $\begin{array}{c}\text { Sexo masculino } \\
(\%)\end{array}$ & $\begin{array}{c}\text { Sexo feminino } \\
(\%)\end{array}$ \\
\hline 16,13 & 83,87 \\
\hline 24,37 & 75,63 \\
\hline 20,16 & 79,84 \\
\hline
\end{tabular}

Frequência genotípica do sexo masculino Tabela 2 no Paraná, em Santa Catarina e no total

\begin{tabular}{|c|c|c|}
\hline $\begin{array}{c}\text { Frequência do } \\
\text { sexo masculino }\end{array}$ & $\begin{array}{c}\text { Homozigoto } \mathrm{G} \\
(\%)\end{array}$ & $\begin{array}{c}\text { Heterozigoto } \\
(\%)\end{array}$ \\
\hline Paraná & 80 & 20 \\
\hline Santa Catarina & 82,76 & 17,24 \\
\hline Total & 81,64 & 18,36 \\
\hline
\end{tabular}

\section{Santa Catarina}

w Heterozigoto $=$ Homozigoto $\mathrm{G}$

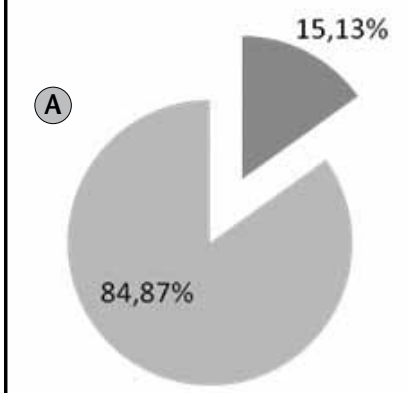

\section{Paraná}

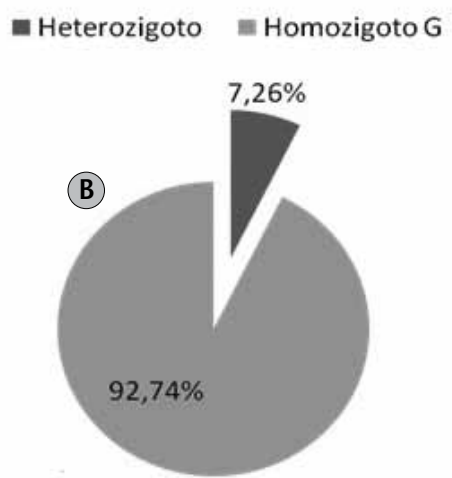

\section{Total}

= Heterozigoto $=$ Homozigoto G

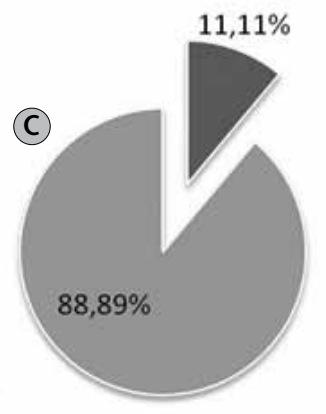

Figura - Frequência genotípica encontrada nos indivíduos dos estados de Santa Catarina e do Paraná 
Os indivíduos do sexo feminino apresentavam 90,72\% do genótipo homozigoto $G$, enquanto $9,28 \%$ apresentavam genótipo heterozigoto. Em relação a cada estado, essa proporção apresentava variação maior se comparada com a variação da proporção da amostra de indivíduos masculinos. Assim, no estado do Paraná, 95,19\% da amostra feminina possuíam genótipo homozigoto $G$, enquanto $4,81 \%$, genótipo heterozigoto. No estado de Santa Catarina, 85,56\% da amostra de indivíduos do sexo feminino apresentavam genótipo homozigoto G e 14,44\%, genótipo heterozigoto (Tabela 3).

\begin{tabular}{l|c|c|} 
& \multicolumn{3}{l}{$\begin{array}{l}\text { Frequência genotípica do sexo feminino } \\
\text { Tabela } 3\end{array}$} & no Paraná, em Santa Catarina e no total \\
\hline Frequência do & $\begin{array}{c}\text { Homozigoto G } \\
(\%)\end{array}$ & $\begin{array}{c}\text { Heterozigoto } \\
(\%)\end{array}$ \\
sexo feminino & 95,19 & 4,81 \\
\hline Paraná & 85,56 & 14,44 \\
\hline Santa Catarina & 90,72 & 9,28 \\
\hline Total & & \\
\hline
\end{tabular}

Em relação às frequências alélicas, 94,44\% para alelo $\mathrm{Ge}$ $5,56 \%$ para alelo A. Na amostra oriunda do estado do Paraná, $96,37 \%$ para alelo G e 3,63\% para alelo A. Na amostra do estado de Santa Catarina, obtivemos $92,44 \%$ de frequência alélica para alelo $\mathrm{G}$ e 7,56\% para alelo A (Tabela 4). $\mathrm{Na}$ amostra do sexo masculino, obtivemos $90,81 \%$ de frequência alélica para alelo G e 9,19\% para o alelo A. Na amostra feminina, 95,36\% de frequência alélica para alelo $G$ e 4,64\% para o alelo A (Tabela 5).

Frequência alélica comparando os resultados encontrados no Paraná, em

Tabela 4 Santa Catarina e no total

\begin{tabular}{l|c|c}
\hline \multicolumn{1}{c|}{$\begin{array}{c}\text { Frequência } \\
\text { alélica }\end{array}$} & $\begin{array}{c}\text { Alelo G } \\
(\%)\end{array}$ & $\begin{array}{c}\text { Alelo A } \\
(\%)\end{array}$ \\
\hline Paraná & 96,37 & 3,63 \\
\hline Santa Catarina & 92,44 & 7,56 \\
\hline Total & 94,44 & 5,56 \\
\hline
\end{tabular}

\section{Frequência alélica comparando}

os resultados encontrados no sexo

Tabela 5 masculino, no sexo feminino e no total

\begin{tabular}{l|c|c}
\hline \multicolumn{1}{c|}{$\begin{array}{c}\text { Frequência } \\
\text { alélica }\end{array}$} & $\begin{array}{c}\text { Alelo G } \\
(\%)\end{array}$ & $\begin{array}{c}\text { Alelo A } \\
(\%)\end{array}$ \\
\hline Sexo masculino & 90,81 & 9,19 \\
\hline Sexo feminino & 95,36 & 4,64 \\
\hline Total & 94,44 & 5,56 \\
\hline
\end{tabular}

\section{Discussão}

A frequência genotípica para genótipo homozigoto G mostrou-se superior no estado do Paraná (92,74\%) em relação à Santa Catarina (84,87\%). Em contrapartida, o genótipo heterozigoto mostrou frequência maior no estado de Santa Catarina $(15,13 \%)$ que no Paraná $(7,26 \%)$. A frequência alélica corroborou esses fatos, visto que a frequência alélica para alelo A foi maior em Santa Catarina $(7,56 \%)$ que no Paraná $(3,63 \%)$, enquanto com o alelo $G$ foi o oposto: 92,44 em Santa Catarina e 96,37\% no Paraná.

Essa mutação encontra-se com maior frequência na população caucasiana e ainda não foi encontrada em pacientes negros e asiáticos(6, 15). Isso sugere o porquê da frequência do alelo A ser maior no estado de Santa Catarina que no estado do Paraná, uma vez que Santa Catarina possui população de descendentes caucasianos maior que no Paraná.

No trabalho realizado em Pernambuco, a frequência genotípica para genótipo heterozigoto foi de $6 \%$ (Ramos, et al. 2008), demonstrando frequência muito inferior para o mesmo genótipo em Santa Catarina. Mesmo a população somada dos dois estados demonstrou frequência maior do que a apresentada no trabalho(11). $\mathrm{O}$ mesmo estudo realizado no centro-sul do Chile, em uma população não nativa, mostrou frequência de 1,33\% para esse mesmo genótipo ${ }^{(8)}$.

Uma pesquisa realizada na população geral e nos casos de trombose generalizada profunda na Espanha mediterrânea mostrou frequência de 5,3\% para genótipo heterozigoto nas duas populações ${ }^{(3)}$. Outro trabalho realizado em Belém-PA demonstrou frequência de $2 \%$ para genótipo heterozigoto ${ }^{(14)}$. Esse mesmo estudo realizado em Minas Gerais mostrou frequência de 5,9\% para genótipo heterozigoto ${ }^{(5)}$. Portanto, em relação aos trabalhos citados, a população dos estados do Paraná e de Santa Catarina mostrou maior frequência para genótipo heterozigoto e, consequentemente, frequência maior no alelo $A$, justamente por esse genótipo ser mais comum em populações caucasianas. Sabendo que existiu forte colonização europeia nesses estados, principalmente de alemães e italianos, foi esperado que essa população mostrasse frequência para genótipo heterozigoto, principalmente em relação aos estados de Pernambuco, do Pará e de Minas Gerais.

Todos os trabalhos mencionados utilizaram a técnica de polimorfismo de tamanho de fragmentos de restrição 
em cadeia da polimerase (RFLP-PCR), com sensibilidade inferior comparada com a técnica de RT-PCR. Isso pode ser uma das prováveis causas da baixa frequência nos estudos do genótipo heterozigoto verificado nos trabalhos citados.

\section{Conclusão}

O estudo realizado mostrou uma variação muito grande na frequência do genótipo heterozigoto em amostras do estado de Santa Catarina. Em trabalhos anteriores, foi verificado que essa mutação incide em maior proporção na população caucasiana.

Conclui-se que a frequência do alelo $A$ é maior no estado de Santa Catarina devido à forte colonização europeia, principalmente por alemães e italianos. Também podemos mencionar que a técnica utilizada, RT-PCR, possui sensibilidade maior em relação a outras técnicas utilizadas para esse estudo, contribuindo com altas taxas do genótipo heterozigoto.

Justamente por nunca ter sido realizado um estudo a respeito dessa mutação no sul do Brasil, esses dados servirão como mais um recurso de pesquisa a ser consultado, contribuindo para o banco de dados dessa região.

Este trabalho mostrou que é recomendável que se faça a identificação do genótipo para esse gene em pacientes com suspeita ou sinais de trombofilia, principalmente nesses dois estados, que mostraram alta frequência no genótipo heterozigoto, exatamente por apresentarem frequência genotípica maior para genótipo heterozigoto e, consequentemente, frequência alélica maior para o alelo A em relação às demais populações nos outros trabalhos que foram comparados com este. Portanto, é importante o diagnóstico laboratorial para esse gene nos pacientes com suspeita de trombofilia.

\section{Referências}

1. ARRUDA, V. R. et al. Prevalence of the prothrombin gene variant (nt20210A) in venous thrombosis and arterial disease. Thromb Haemost, v. 78, n. 6, p. 1430-3, 1997.

2. DUQUE, F. L. V.; MELLO, N. A. Trombogênese-trombofilia. J Vasc Bras, v. 2, n. 2, p. 105-18, 2003.

3. FRANCĖS, F. et al. Comparación de las frecuencias de los alelos factor $V$ Leiden (G1691A) y protrombinaG20210A entre pacientes con trombosis venosa profunda y población general meditérranea española. Rev Méd Chile, v. 134, p. 13-20, 2006.

4. GINZINGER, D. G. et al. Gene quantification using realtime quantitative PCR: an emerging technology hits the mainstream. Experimental Hematology, v. 30, p. 503-12, 2002.

5. GUIMARÃES, S. P. et al. Mutações predisponentes à trombofilia em indivíduos de Minas Gerais-Brasil com suspeita clínica de trombose. Rev Bras Hematolo Hemoter, v. 31, n. 1, p. 19-24, 2009.

6. HIRA, B. et al. Absence of factor V Leiden, thrombomodulin and prothrombin gene variants in black South African women with pre-eclampsia and eclampsia. BJOG, v. 110, p. 327-8, 2003.

7. MATEO, J. et al. Increased risk of venous thrombosis in carriers of natural anticoagulant deficiencies: results of the family studies of the Spanish Multicenter Study on Thrombophilia (EMET study). Blood Coagul Fibrinolysis, v. 9, n. 1, p. 71-7, 1998.

8. PALOMO, I. et al. Low prevalence of factor $V$ Leiden and the prothrombin G20210A mutation in a healthy population from central-south region of Chile. Rev Bras Hematolo Hemoter, v. 31, n. 3, p.143-6, 2009.
9. PIHUSCH, B. et al. Thrombophilic gene mutations and recurrent spontaneous abortion: prothrombin mutation increases the risk in the first trimester. J Repro Immul, v. 46, n. 2, p. 124-31, 2001.

10. POORT, S. R. et al. A common genetic variation in the 3' untranslated region of the prothrombin gene is associated with elevated prothrombin levels and a increase in venous thrombosis. Blood, v. 88, n. 10, p. 3698-703, 1996.

11. RAMOS, C. P. et al. Protrombina mutante em indivíduos sob investigação de trombofilia. J Bras Patol Med Lab, v. 44, n. 2, p. 79-82, 2008.

12. SAMBROOK, J.; FRITSCH, E. F.; MANIATIS, T. Molecular cloning a laboratory manual. 2. ed. USA: Cold Spring Harbor Laboratory Press, 1989. 1886 p.

13. SELIGSOHN, U.; LUBETSKY, A. Genetic susceptibility to venous thrombosis. N Engl J Med Overseas Ed, v. 344, n. 16, p. 1222-31, 2001.

14. YOSHIOKA, F. K. N. et al. Prevalence of hereditary risk factors for thrombophilia in Belém, Brazilian Amazon. Genetics and Molecular Biology, v. 29, n. 1, p. 38-40, 2006.

15. ZIVELIN, A. et al. A single genetic origin for the common prothrobotic G20210A polymorphism in the prothrombin gene. Blood, v. 92, n. 4, p. 1119-24, 1998.

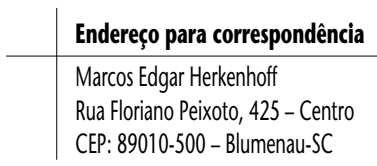

